http://dx.doi.org/10.30681/23588403v12i03133140

\title{
ANÁLISE PSICANALÍTICA DO CONTO A VERDADEIRA NOIVA, DOS IRMÃOS GRIMM
}

Thiago SILVA (IFMA) ${ }^{1}$

Data de recebimento: $24 / 09 / 2018$

Aceite: 12/11/2018

Resumo: Este trabalho, que é de natureza bibliográfica, propõe a análise psicanalítica do conto de fadas intitulado A Verdadeira Noiva, dos irmãos Grimm ${ }^{2}$, sob o enfoque psicanalítico lastreado, principalmente, nos estudos de Sigmund Freud e Bruno Bettelheim (2004). A partir das análises realizadas, percebe-se que os contos de fadas, de maneira geral, são excelentes obras de arte que possuem uma carga simbólica, sobretudo psicológica, muito rica, capaz de traduzir os conflitos internos da criança.

Palavras-chave: Análise Psicanalítica. A Verdadeira Noiva. Conto de Fada.

Abstract: This work, which is of a bibliographical nature, proposes the psychoanalytic analysis of the fairy tale entitled The True Bride, by the Grimm brothers, under the psychoanalytic approach, mainly based on the studies of Sigmund Freud and Bruno Bettelheim. From the analyzes carried out here, it can be seen that fairy tales, in general, are excellent works of art that have a symbolic, especially psychological, and very rich load, capable of translating the internal conflicts of the child.

Keywords: Psychoanalytic Analysis. The True Bride. Fairy tale.

\section{Introdução}

Antes de iniciar as análises do conto A Verdadeira Noiva, dos irmãos Grimm, tornase imperiosa a realização de um retrospecto sintético sobre a história dos contos de fadas, enquanto gênero infantil, haja vista que nos dias hodiernos, sua função é bem distinta se comparada à que era praticada há dois ou três séculos.

Antigamente, esses contos não tinham uma função direcionada a entreter as crianças, aliás, a literatura infantil nasceu com as transformações sociais e adoção de uma nova concepção de criança, na Europa dos séculos XVIII e XIX, o que levou ao surgimento de uma literatura para esse público. Contudo, há que se pontuar, que não se produz uma literatura exclusiva às crianças, o que existem são adaptações de contos populares, os quais circulavam no contexto do camponês. O iniciador dessas adaptações foi o francês Charles Perrault, o qual

\footnotetext{
${ }^{1}$ Mestre em Letras. Técnico em Assuntos Educacionais do Instituto Federal do Maranhão - Campus Barra do Corda. Barra do Corda - MA, Brasil, e-mail thiago.silva@ifma.edu.br

${ }^{2}$ Esse conto foi lido no seguinte site https://www.grimmstories.com/pt/grimm_contos/a_verdadeira_noiva
} 


\section{Revista de Estudos Acadêmicos de Letras}

tem levado o título de pai da literatura infantil. Seguidamente, vieram os Irmãos Grimm e outros.

As crianças, na concepção tradicional, eram tratadas como "adultos em miniaturas", e, por isso, não recebiam atenção especial, inclusive nos aspectos cognitivos. Nessa esteira, Cademartori (1986, p. 38 - 39) nos diz que "a criança, na época, era concebida como um adulto em potencial, cujo acesso ao estágio dos mais velhos só se realizaria através de um longo período de maturação". Com a mudança dessa concepção, a criança, com demarcações etárias, passou a ser "enxergada" pelos adultos.

Com essa nova conjuntura, os medos e angústias vividos na infância tornaram-se objetos de análise com vista ao alcance de um "antídoto" para curá-los ou ao menos ajudá-las a desenvolver-se sem maiores complicações. Nesse aspecto, os contos de fadas, quando apresentados a elas, as ajudam a se tornarem mais sensíveis e otimistas, afinal, a fantasia é indispensável à criança.

As estórias de fadas, normalmente, iniciam com uma narrativa simples e partindo sempre de um problema ligado à realidade, como por exemplo, a perda dos pais. No decorrer desse tipo de história, procurando contornar esses conflitos, surgem as figuras sobrenaturais: fadas e anões. Ao final da narrativa, após o período de maturação, onde os medos e aflições são resolvidos, há o retorno à realidade, em que os heróis se casam ou retornam ao lar.

No livro A psicanálise dos Contos de Fadas, Bettelheim (2004, p.19) diz:

Só partindo para o mundo é que o herói dos contos de fada (a criança) pode se encontrar; e fazendo-o, encontrará também o outro com quem será capaz de viver feliz para sempre; isto é, sem nunca mais ter de experimentar a ansiedade de separação. O conto de fadas é orientado para o futuro e guia a criança - em termos que ela pode entender tanto na sua mente inconsciente quanto consciente $-\mathrm{a}$ ao abandonar seus desejos de dependência infantil e conseguir uma existência mais satisfatoriamente independente.

Em outro trecho, esse mesmo autor (p.20) nos fala que:

Enquanto diverte a criança, o conto de fadas a esclarece sobre si mesma, e favorece o desenvolvimento de sua personalidade. Oferece significado em tantos níveis diferentes, e enriquece a existência da criança de tantos modos que nenhum livro pode fazer justiça à multidão e diversidade de contribuições que esses contos dão à vida da criança.

Dessa forma, os contos de fadas mostram-se indispensáveis às crianças em crescimento, pois vão além de ensinamentos sobre normas e condutas sociais, podendo ser considerados terapêuticos, isto é, "os processos internos são externalizados e tornam-se compreensíveis enquanto representados pelas figuras da estória e seus incidentes." (BETTELHEIM, 2004, p. 33). 


\section{Revista de Estudos Acadêmicos de Letras}

Nessa perspectiva, o presente trabalho, que é de natureza bibliográfica, propõe a análise psicanalítica do conto intitulado A Verdadeira Noiva, dos irmãos Grimm, sob o enfoque psicanalítico lastreado, principalmente, nos estudos de Sigmund Freud e Bruno Bettelheim (2004).

\section{Um breve resumo do conto $A$ verdadeira noiva}

Este conto, dos Irmãos Grimm, traz à cena a história de uma jovem linda e bondosa, e no polo oposto, está a sua madrasta, que possuía características conflitantes, tais como: perversa, insatisfeita e descontente. A madrasta odiava a enteada e, por isso, a enchia de trabalhos árduos, sobrecarregando-a com o propósito de tornar a vida dela uma "vida impossível".

O primeiro trabalho dado à jovem foi o desfiamento de doze quilos de penas, acompanhado da promessa de que se não cumprisse a tarefa, a enteada apanharia. Bastante desesperada, a moça suplicou: "Não haverá mesmo ninguém neste mundo de Deus que tenha pena de mim? Em seguida, aparece uma senhora de idade, a julgar pelo nome a ela atribuído, "velha", que a oferece ajuda, dizendo: "Consola-te, minha menina, aqui estou para ajudar-te."3 A menina sente-se segura e segreda suas angústias à velha senhora. A velha então pediu à jovem que descansasse e que não se preocupasse com o serviço, pois ela o faria. Ao acordar, a menina viu que a velha havia desaparecido, entretanto, o trabalho estava pronto e o quarto todo organizado.

Posteriormente, a madrasta, ao entrar no quarto, observou que a enteada concluiu a tarefa, o que lhe causou bastante admiração. Contudo, esse sentimento não abrandou sua cólera, pelo contrário, ela se multiplicou.

No dia seguinte, a madrasta ordenou à enteada outro serviço: “Aqui tens uma colher; exijo que tires com ela toda a água do grande lago que há perto do jardim”. Ao iniciar o serviço, a menina observou que a colher estava furada, mas isso não importava muito, pois mesmo que não estivesse, ela jamais conseguiria realizar a tarefa, mas mesmo assim, a jovem iniciou o trabalho com afinco.

A velha que a ajudara no dia anterior reapareceu e, após saber de tudo, pediu à moça que dormisse no bosque, enquanto ela fazia a tarefa. Ao acordar, a enteada vislumbrou o serviço concluído. Em seguida, comunicou à madrasta que terminou o trabalho; esta, porém, se enfureceu ainda mais e arquitetou dar à jovem um serviço ainda mais difícil.

${ }^{3}$ Texto reproduzido integralmente tal como está no texto pesquisado 


\section{Revista de Estudos Acadêmicos de Letras}

O terceiro trabalho foi construir, em um único dia, numa planície cheia de pedras, um castelo, o que fez com que a menina redarguisse: "Como é possível executar uma obra desse vulto?" A madrasta esbravejou: "Não admito que me contradigas! Se tens capacidade para esvaziar um lago com uma colher furada, deves ter capacidade, também, para construir um castelo. " A menina iniciou sua nova tarefa tentando mover as pedras, mas não logrou sucesso, então, pôs-se a chorar, mas seu íntimo dava como certa a ajuda da velha. Esta apareceu e solicitou à moça que dormisse em uma sombra enquanto ela fazia o trabalho. Concluída a obra do castelo, a jovem foi ao encontro da madrasta para comunicá-la.

A madrasta, com a enteada, vai ao castelo fiscalizar a obra, e lá não acha um só erro. Posteriormente, após indicação do caminho, vai à adega, que ficava na parte de baixo do castelo fantástico. A madrasta abriu a porta e iniciou a descida, mas para sua pouca sorte, a porta (alçapão) caiu em suas costas fazendo-a rolar escada a baixo. A enteada correu nervosa na tentativa de socorrê-la, porém, a mesma já estava morta.

Agora, com a morte da madrasta, o castelo e todas as suas benesses ficaram para a menina de rara beleza. Com isso, corre a notícia na cidade de que a menina bonita estava rica, boato que lhe rendeu muitos pretendentes querendo desposá-la. Ela rejeitou todos já que não agradavam a seu coração. Por fim, apresentou-se o filho de um rei muito poderoso que soube agradar-lhe. Noivaram, e, agora, o jovem príncipe disse que teria que voltar ao seu pai para pedir-lhe consentimento para casar-se, deixando a ela a orientação de que ela deveria aguardálo debaixo de uma tília, pois ele voltaria em poucas horas.

Na partida do príncipe, a moça beijou a face esquerda dele, fazendo-lhe a seguinte recomendação: "Conserva-te fiel ao nosso amor e não permitas que mulher alguma te beije nesta face".

Passaram-se três dias e o príncipe não voltou, em aflição, a noiva achando que algo poderia ter acontecido, embrulhou três vestidos escolhidos entre os mais lindos que tinha e um punhado de pedras preciosas e foi procurá-lo.

Andou muito, mas ninguém sabia informar nada sobre o paradeiro do príncipe. Ela decide empregar-se como pastora na casa de um camponês. As pedras preciosas e os vestidos, ela enterrou-os. Triste por pensar que o príncipe havia a esquecido, ela cantava sempre a um bezerrinho, o qual tinha muita afeição a ela, a seguinte música: "Bezerrinho, bezerrinho, ajoelha, não esqueças a tua pastora, como o príncipe esqueceu a fiel noiva de outrora! ”

Por vários anos ela ficou cuidando dos bezerros, foi quando correu o boato de que o filho do rei estava preste a casar-se. Certo dia, o príncipe passou pelo caminho onde ela estava 


\section{Revista de Estudos Acadêmicos de Letras}

tocando os bois, mas o príncipe nem olhou para ela. No dia seguinte, o príncipe passou novamente pelo caminho; ela cantou a mesma música ao bezerrinho, e o príncipe reconheceu a sua voz, porém, seguiu seu caminho.

O castelo estava em festa, que duraria três dias; a pastora então decidiu vestir-se com um dos seus vestidos elegantes e foi ao castelo. Ao chegar lá, todos ficaram impressionados com sua beleza, inclusive o príncipe. Ao final da noite ela retornou para casa. Na noite seguinte, ela foi novamente à festa, e mais uma vez o príncipe só quis dançar com ela. Ao final da noite, o príncipe a fez prometer que ela voltaria para a última noite de festa. E assim ela fez. Quando dançavam, o príncipe a perguntou quem era ela, pois parecia que a moça o conhecia há tempos; ela, então disse: "Já não te lembras o que fiz e disse quando nos despedimos? " Em seguida, ela o beija na face esquerda do rosto, exatamente como havia feito antes. Foi como se uma venda lhe caísse dos olhos e o príncipe reconheceu a sua verdadeira noiva. Às pressas rumaram ao castelo maravilhoso, e lá, ao subir as escadarias, as flores desabrochavam, foi então que se casaram.

\section{Análises e discussões}

Devido à alteração substancial na concepção de criança, explicitada na introdução deste texto, a psicanálise pôde passar a interpretar as estórias de fadas, encontrando nelas elementos de seus conceitos mais fundamentais, entre eles, o Complexo de Édipo.

A despeito desse fenômeno, de forma concisa, sabe-se que ele se inicia com a sexualização dos pais e termina com a dessexualização dos mesmos. Este nome é inspirado na tragédia grega Édipo Rei, utilizada por Freud como uma metáfora desse amor direcionado ao genitor do sexo oposto.

Nesse complexo, a criança, em especial a menina, passa por um momento de rivalidade com o genitor do mesmo sexo. Nasio (2007, p.56) diz que essa "É a idade em que as filhas adoram observar a mãe se maquiando ou se embelezando - ainda que a admiração pela mãe seja duplicada por uma forte rivalidade: toda mãe é então, para a filha, tanto um ideal quanto uma temível rival."

Assim sendo, esta rivalidade é revelada nas figuras que povoam os contos de fadas. Para as meninas, aparecem as madrastas e as bruxas más, que anseiam por destruir ou roubar seus atributos de mulher desejável pelos homens. À guisa do exemplo, há em outro conto, o da Branca de Neve, a imagem da madrasta que tem medo de perder o posto de mulher mais bela do reino para a enteada, e para que isso não aconteça, ela usa a maça envenenada para matar a moça. A maçã, neste contexto, representa a rivalidade entre as duas. 


\section{Revista de Estudos Acadêmicos de Letras}

No conto A Verdadeira Noiva, objeto desta análise, observa-se que não é diferente, já que existe a rivalidade, a qual é representada pela madrasta que a todo custo tenta fazer sucumbir a enteada, dando-lhe trabalhos humanamente impossíveis.

Apesar de não ser o foco de este trabalho dar relevo ao complexo de Édipo porque passam os meninos, importa dizer que o mesmo complexo, com algumas diferenças, também os alcança. Nas estórias, surgem os ogros e gigantes, que representam o pai da visão primitiva da criança, aquele que é dono de tudo, inclusive da mãe e do castelo (da casa). Um exemplo disso é encontrado no conto de João e o Pé de Feijão, onde o menino volta para a casa carregando seus tesouros para desfrutar deles com sua mãe, após ter vencido o gigante. Isso permite inferir que João é um pequeno Édipo, embora não tenha feito sexo com a mãe.

A partir dos exemplos citados, conclui-se que tanto a madrasta quanto o gigante representam a mãe e o pai, respectivamente, rivais edípicos das crianças. Essa transformação dos pais em outros seres pode ser um recurso para aliviar o sofrimento causado pelo conflito entre o pai e o filho e, entre a mãe e a filha.

Nesse sentido, uma análise mais atenta dos papeis desempenhados pela madrasta e pela velha no conto $A$ Verdadeira Noiva, infere-se que a madrasta é a projeção da mãe má, que apesar de sê-la, sua maldade é necessária para o amadurecimento da filha (a enteada), considerando que a moça só alcançou sua felicidade (casar-se com o príncipe) graças à imposição do terceiro trabalho, qual seja: a construção de um castelo. Por outro lado, a imagem criada a partir da velha (a fada) sugere a da mãe boa, amorosa e protetora. Bettelheim (2004, p. 98) observou essa possibilidade ao dizer que "embora a mãe seja na maioria das vezes a protetora dadivosa, ela pode se transformar na cruel madrasta se for má a ponto de negar ao menino algo que ele deseja."

Assim sendo, a criança, a partir dessa possibilidade dual, percebe que o fato de a mãe às vezes lhe negar alguma coisa, isso não coloca, necessariamente, em perigo a imagem boa que ele tem dela. Nessa linha, Bettelheim (p.98) afirma que:

Longe de ser um expediente usado apenas por contos de fadas, esta divisão de uma pessoa em duas para manter a boa imagem sem contaminação ocorre a muitas crianças como uma solução para um relacionamento muito difícil de conduzir ou compreender.

O salvamento da imagem da mãe boa fica evidente, no conto sob análise, quando a enteada corre aflita para socorrer sua madrasta que caiu das escadas, ação que poderia parecer incomum, haja vista que ela era muito má à moça, e esta por sua vez, deveria desejar a morte daquela. Aproveitando esse ponto da estória, interpreta-se a queda, escada a baixo, da madrasta 
e, consequentemente, sua morte como o momento em que a criança consegue sepultar o conflito gerado pelas negativas da mãe, e, assim, preserva o seu lado positivo.

Outro símbolo bastante presente nos contos de fadas é o do sono. Neste conto que se analisa, na sua primeira metade, a jovem bela adormece três vezes e, quando acorda, os seus trabalhos já estavam concluídos. Com um olhar atento, infere-se que os trabalhos representam na verdade os problemas, conflitos e desafios, por vezes internos, que se impõem à criança; por outro lado, o sono simboliza o renascimento, pois "cada novo despertar simboliza a conquista de um estado mais adiantado de maturidade e compreensão. " (BETTELHEIM, 2004, p.254), isto é, maturidade emocional.

Os conceitos da psique humana cunhados por Freud e que podem ser utilizados na análise dos contos de fadas, são aqueles que tratam do Id, Ego e Superego.

A partir da interação entre os lados conscientes e inconscientes do cérebro humano, Freud, em 1923, identificou a existência de sentimentos primitivos, pulsões desenfreadas, regidos pelo princípio do prazer, o qual denominou de $I d$. O outro, que também se encontra no inconsciente é o superego, que são os pensamentos que colidem com os do $I d$, isto é, são antagônicos. O superego é formado durante o complexo de Édipo e, por isso, é oriundo dos valores morais e éticos imposto ao humano quando ainda é criança. Por fim, tem-se o Ego, o qual está na parte consciente do cérebro. Este age como um mediador entre as solicitações do Id e do Superego com relação ao mundo externo.

No conto A Noiva Verdadeira, o número três (três trabalhos, três vestidos, três fases da vida - criança/enteada, pastora e noiva/esposa - mais três dias à espera do príncipe e três noites de festa) não é mera alegoria, antes, ele se relaciona com o Id, Ego e Superego. O Id está no desejo desenfreado da pastora de encontrar o príncipe, levando-a a correr perigo, haja vista ela ter usado, na primeira noite de festa, um vestido de sóis de ouro, e "felizmente, em meio às trevas ninguém lhe prestou atenção".

Uma última análise cabível envolve a questão sexual, também presente neste conto, quando a noiva, após um processo de maturação, está pronta para casar-se. Isso é observado no trecho que diz que "ao subir as escadarias, as flores desabrochavam". A imagem que se cria a partir desse evento tem um formato fálico, que vai "excitando", ou seja, desabrochando, à medida que eles sobem as escadarias rumo ao castelo fantástico. 


\section{Algumas considerações}

A partir das análises aqui realizadas, percebe-se que os contos de fadas, de maneira geral, são excelentes obras de arte que possuem uma carga simbólica, sobretudo psicológica, muito rica, capaz de traduzir os conflitos internos da criança. Dessa forma, esses contos tratam, primordialmente, por meio de símbolos, dos processos interiores.

Não há dúvida de que as crianças entendem de forma satisfatória a linguagem simbólica dos contos. Não esqueçamos que o "faz de conta" ganha "vida" por obra delas, pendendo entre a imaginação e a realidade.

Os textos de Bettelheim, que versam sobre os aspectos psicanalíticos dos contos de fadas, revelam que a fantasia é o caminho possível para alcançar o enfrentamento dos conflitos internos (angústia, dilemas edípicos, rivalidades fraternas, etc.).

\section{Referências}

BETTELHEIM, B. A psicanálise dos contos de fadas. Rio de Janeiro: Paz e Terra, 2004.

CADEMARTORI, L. O que é literatura infantil. São Paulo: Brasiliense 1986.

NASIO, J.D. Édipo: o complexo do qual nenhuma criança escapa. Tradução de André Telles. Rio de Janeiro: Jorge Zahar Editora, 2007. 